\title{
MicroRNA Implications across Neurodevelopment and Neuropathology
}

\author{
Sabata Martino, ${ }^{1}$ Ilaria di Girolamo, ${ }^{1}$ Antonio Orlacchio, ${ }^{2,3}$ Alessandro Datti, ${ }^{1}$ \\ and Aldo Orlacchio ${ }^{1}$
}

${ }^{1}$ Dipartimento di Medicina Sperimentale e Scienze Biochimiche, Sezione di Biochimica e Biologia Molecolare,
Università di Perugia, Via del Giochetto, 06126 Perugia, Italy
${ }^{2}$ Laboratorio di Neurogenetica, CERC-IRCCS Santa Lucia, Via del Fosso di Fiorano 64, 00143 Rome, Italy
${ }^{3}$ Dipartimento di Neuroscienze, Università di Roma "Tor Vergata", Viale Oxford 81, 00133 Rome, Italy

Correspondence should be addressed to Aldo Orlacchio, orly@unipg.it

Received 2 February 2009; Revised 11 May 2009; Accepted 20 July 2009

Recommended by Ravi Sachidanandam

\begin{abstract}
MicroRNAs (miRNAs) have rapidly emerged as biologically important mediators of posttranscriptional and epigenetic regulation in both plants and animals. miRNAs function through a variety of mechanisms including mRNA degradation and translational repression; additionally, miRNAs may guide gene expression by serving as transcription factors. miRNAs are highly expressed in human brain. Tissue and cell type-specific enrichments of certain miRNAs within the nervous system argue for a biological significance during neurodevelopmental stages. On the other hand, a large number of studies have reported links between alterations of miRNA homeostasis and pathologic conditions such as cancer, heart diseases, and neurodegeneration. Thus, profiles of distinct or aberrant miRNA signatures have most recently surged as one of the most fascinating interests in current biology. Here, the most recent insights into the involvement of miRNAs in the biology of the nervous system and the occurrence of neuropathological disorders are reviewed and discussed.
\end{abstract}

Copyright (C) 2009 Sabata Martino et al. This is an open access article distributed under the Creative Commons Attribution License, which permits unrestricted use, distribution, and reproduction in any medium, provided the original work is properly cited.

\section{Introduction}

microRNAs (miRNAs) are small, noncoding oligoribonucleotides of $\sim 21-22 \mathrm{nt}$ which regulate gene expression through the assembly of an RNA-induced silencing complex (RISC). In particular, the downstream effects of miRNAs relate to the fate of target mRNA, which may be subjected to endonucleolytic cleavage, enrolled into a faulty translational process or, as surprisingly shown in most recent studies, translationally enhanced [1-12]. Each of the hundreds of miRNAs present in mammalian genomes can potentially modulate an impressively large number of target genes, thereby depicting a highly versatile network with the capacity to effectively control and modify the biochemical wiring and, in turn, the phenotypic outcome of a cell $[1,8]$.

It is now well established that miRNAs are involved in disparate physiological functions, such as developmental transitions and neuronal patterning, apoptosis, fat metabolism, and regulation of hematopoietic lineage differentiation. For example, miRNAs are key regulators of the nervous system in the worm and brain morphogenesis in the fish and show distinct expression patterns during mammalian brain development [13].

A clear understanding of the functional impact of miRNAs on brain neurodegeneration is an intriguing, yet rather elusive, matter of study. However, the current literature shows clear evidence that tightly controlled miRNA expression is required for proper neurodevelopment and, conversely, that specific miRNA dysregulation is likely linked to the pathogenesis of neurodisorders.

\section{2. miRNA Biogenesis}

Biogenesis and silencing mechanisms of miRNAs were recently revisited by Carthew and Sontheimer, who have highlighted common themes and unique features of both 


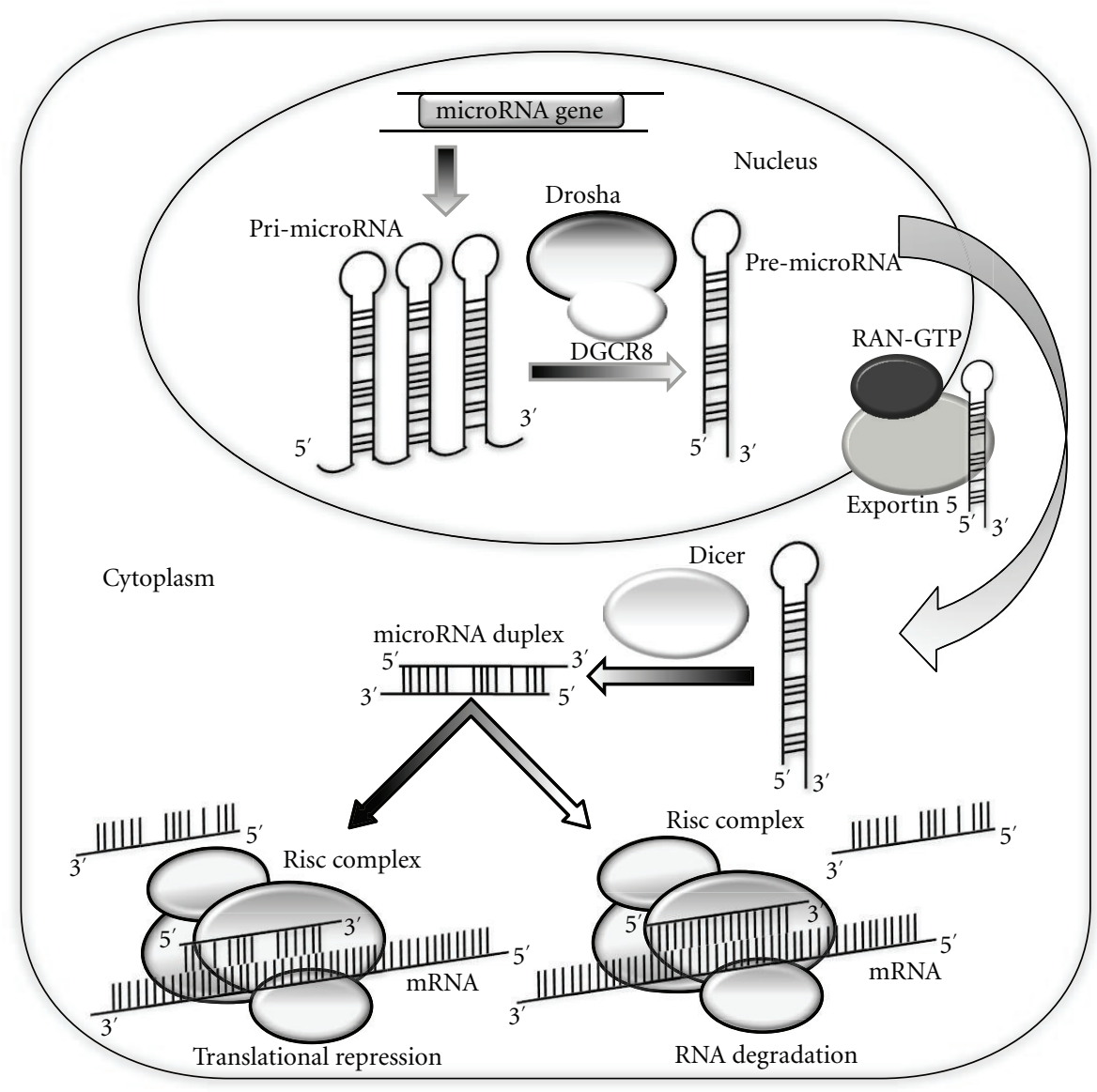

FIgURE 1: The biogenesis of miRNAs. Shown are the key steps of miRNA biogenesis in mammalian cells (reviewed in [14, 15]).

miRNA- and siRNA-related pathways (see Figure 1 and [14]). In either context, the molecular events that span from miRNA transcription towards RNA degradation are complex and imply an intricate interplay of molecular events to ensure accurate and efficient regulation of gene expression [16].

In mammals, $80 \%$ of miRNA genes are located within introns of longer primary transcripts that can be either protein-coding or mRNA-like transcripts; the majority of these are produced by RNA polymerase II [17-20], while a minor group of genes, characterized by Alu sequences, is instead transcribed by Pol III [21]. Thus, Pol II-associated transcription factors may regulate the expression of the majority of miRNA genes in a tissue- and/or cell-specific fashion [22].

While transcription of intergenic miRNA genes implies usage of own promoters, intronic miRNAs are transcribed with their host genes and seem to be cotranscriptionally processed prior to the removal of the host intron [18]. Typically, primary miRNA transcripts or pri-miRNAs are composed of a double-stranded stem of 33 base pairs, a terminal loop, and two flanking, single-stranded segments which are subject to cleavage, in the nucleus, by a protein complex called Microprocessor. This is composed of a nuclear member of the RNA III family (Drosha) associated with a cofactor (DGCR8) for efficient and precise processing of pri-miRNAs into 60-70 nt, hairpin-like precursor miRNAs (pre-miRNAs) [23-27].

Interestingly, several pre-miRNAs, known as mirtrons, originate directly from the splicing of pri-miRNAs and are subsequently processed without a requirement for Microprocessor activity. Evidence suggests that this alternative pathway, although rather uncommon, has emerged throughout metazoans prior to the advent of Drosha [28-30].

Through the exportin-5 pathway, pre-miRNAs are then transferred to the cytoplasm where they are further processed by Dicer, a second RNase III complexed with the human immunodeficiency virus transactivating response RNA-binding protein, TRBP [31, 32]. Dicer binds the $3^{\prime}$ overhang of the dsRNA and then excises the terminal loop to produce a mature, single-stranded miRNA duplex of approximately $22 \mathrm{bp}$. This duplex is ephemeral, in that it is rapidly unwound as soon as it associates with an Argonaute protein (Ago). Only one strand of the original dsRNA molecules is incorporated into RISC while the ejected strand, unlike during the siRNA unwinding mechanism, is not degraded by the associated Ago [7, 14-32]. Finally, miRNAs trigger gene silencing through partial base-pairing with the $3^{\prime}$-UTRs of protein-coding mRNAs, thereby preventing translation of targeted mRNAs and/or accelerating their degradation $[15,33]$. 
TABLE 1: miRNAs involved in neurodevelopment.

\begin{tabular}{|c|c|c|c|c|}
\hline miRNA & Species & Target & Function & Reference number \\
\hline miR-iab-4-5p & Drosophila & UBX & Regulation of Hox gene involved in the development of halters & {$[34]$} \\
\hline miR10a & Human & HOXA1 & Downregulation of HOXA1 geneExpression & {$[35]$} \\
\hline lsy-6 & C. elegans & $\operatorname{Cog}-1$ & Required to specify ASEL sensory neuron identity & {$[36,37]$} \\
\hline $\operatorname{miR}-273$ & C. elegans & Die-1 & Expressed in ASER; suppresses ASEL identity & {$[36,38]$} \\
\hline miR-196 & Rodents & HOXB8 & Downregulation of HOXC8, HOXD8 and HOXA7 & [39] \\
\hline $\operatorname{miR}-124$ & Rodents & SCP1 & Neural induction in the spinal cord of developing embryos & {$[40]$} \\
\hline $\operatorname{miR}-124$ & Rodents & SOX9 & $\begin{array}{l}\text { Regulation of the neurogenesis in the SVZ stem cell niche and } \\
\text { neurite outgrowth in neuronal differentiation }\end{array}$ & [41] \\
\hline $\operatorname{miR}-132$ & Rodents & P250GAP & Regulation of the neuronal morphogenesis and circadian clock & {$[42,43]$} \\
\hline miR-219 & Rodents & SCOP & Regulation of the circadian period length & {$[36,43]$} \\
\hline miR-133b & Rodents & Pitx3 & $\begin{array}{l}\text { Regulation of the maturation of midbrain dopaminergic } \\
\text { neurons }\end{array}$ & {$[44]$} \\
\hline $\operatorname{miR}-134$ & Rodents & LimK1 & Modulation of the size of dendritic spines & {$[45]$} \\
\hline
\end{tabular}

The existence of stringent regulatory mechanisms affecting the biogenesis of miRNAs suggests that this pathway plays a crucial role in the control of gene expression and, further downstream, the definition of biological outcomes. In this regard, several examples of double-negative feedback loops have been described, showing that the expression of miRNA genes can be controlled by their own targets [14].

\section{3. miRNAs Play Major Physiological Roles in Neural Development}

In Drosophila, multiple miRNAs interact with different $3^{\prime}$ UTR binding sites to play a cooperative role in the posttranscriptional regulation of nerfin-1, a nuclear regulator of axon guidance, within both the developing central nervous system (CNS) and peripheral nervous system. In species of this organism, the high degree of evolutionary conservation of miRNA-binding sites provides evidence that regulation of the onset and extinction dynamics of nerfin-1 expression is common to all members of the Drosophila genus [46].

As shown in Table 1, the effects of miRNA-mediated modulation of gene expression during multiple steps of neuronal development, from early neurogenesis to synaptogenesis, have been well documented across the animal kingdom [34-45, 47-61].

Strong evidence for a biological role of miRNAs in neural development emerged from their identification within the HOX gene clusters [49]. When ectopically expressed, these miRNAs induce a homeotic mutant phenotype, as shown in Drosophila for miR-iab-4-5p, which reduces endogenous Ubx protein levels, causing halteres to be transformed into wings [34]. In addition, miR-10a targets HOXA1 [35] while miR-196, encoded at three paralogous locations in the A, $\mathrm{B}$, and $\mathrm{C}$ mammalian HOX clusters, directs the cleavage of HOXB8 mRNA and, apparently, downregulates HOXC8, HOXD8, and HOXA7 [39].

The capacity of miRNAs to directly control cell fate decisions and, in turn, specify neuron identity was also shown in Caenorhabditis elegans $[37,38]$. In developing axons, miRNAs may regulate pathfinding, the process by which the circuitry of the nervous system is built. In zebrafish, normal brain morphogenesis is disrupted in the absence of the miRNA-processing enzyme Dicer [50], while the observation that functional RISC complexes can be assembled in rat DRG axons and growth cones is indicative of important roles played by miRNAs in the regulation of axonal mRNA translation [51].

Indeed, the CNS displays a substantial enrichment of miRNA species, of which a considerable number is expressed in a temporally- and/or spatially-controlled fashion, thereby suggesting biological implications for specific developmental stages $[52,53]$. Expression profiling revealed that several species of miRNAs, such as miR-9, miR-124, miR-124a, miR125b, miR-127, miR-128, miR-132, miR-219, and members of the let-7 family, are especially localized in the mouse brain [40-45, 54-61], while the expression of 63 additional miRNAs appears to be widely distributed, although differentially, throughout the CNS [62]. Of these, some are primarily present in the cerebellum (miR-195, miR-497, and miR-30b), others in the medulla oblongata (miR-34a, miR451, miR-219, miR-338, miR-10a, and miR-10b), while a third group (miR-7, miR-7b miR-218, miR-221, miR-222, miR-26a, miR-128a/b, miR-138, and let-7c) appears to be restricted to the hypothalamus [63-66]. In general, regionspecific enrichments reflect expression rates threefold higher compared to average miRNA levels displayed throughout the CNS [67-70].

Conceivably, miRNAs affect patterning mechanisms that specify the fate of neural cells at specific times and within proper locations. For example, an investigation of the expression of 104 miRNAs during murine brain development showed that these were distributed according to specific temporal expression patterns; in particular, the expression of 12 miRNAs was significantly upregulated during embryonic stages while markedly decreased during brain development. The involvement of modulated miRNAs was recapitulated by computational screens aimed at target identification, which revealed that 10 of 12 miRNAs are likely associated with neurogenesis [70]. 
In some instances, the physiological role of a number of miRNAs in neurodevelopment is well-documented. For example, miR-124 controls neurite outgrowth in differentiating mouse P19 cells [71] and stimulates neuronal differentiation in the developing chick spinal cord by counteracting the antineural activity of one of its targets, namely, the small C-terminal domain phosphatase 1 (SCP1) [40]. Furthermore, functional studies in vivo have recently demonstrated that miR-124 controls adult neurogenesis in the mouse subventricular zone via a time-regulated control of neuroblast generation from transit-amplifying precursors. In particular, neuronal differentiation is promoted through downregulation of the transcription factor Sox9, shown to be one of the targets of miR-124 [41, 72]. A second example relates to miR-132, which oversees dendritic morphogenesis by inhibiting translation of the synaptic protein p250GAP, suggesting a key role of miR132 p250GAP pathway in synapse growth and plasticty $[42,43,73]$. Additionally, miR-133b regulates maturation and function of midbrain dopaminergic neurons through a negative feedback affecting the paired-like homeodomain transcription factor Pitx3 [44], while miR-134 activity leads to dendritic spine development through downregulation of the Lim domain kinase$1[45]$.

miRNAs may also play significant roles in apoptosis, which is crucial in neurogenesis and during the subsequent, continued expansion of the brain size following a massive loss of neurons (i.e., 20\%-80\%) typical of embryonic development [74]. It was proposed that several aspects of neuronal function, for example, the control of plasticity, are directly mediated by miRNAs [75].

Instead, not much evidence has yet become available to define the impact of miRNAs on neural induction, namely, the stage when embryonic cells assume a neuronal identity. However, in light of a specific expression in stem cells, it is possible that miRNAs play a role in self-renewal and differentiation events through the regulation of key genes [76], as suggested by the ability of embryonic stem cellspecific miRNAs to enhance murine stem cell reprogram$\operatorname{ming}[77,78]$.

As regards human miRNAs, the miRBase Sequence Database of the Sanger Center (Release 14.0, dated September 2009) contains 706 sequences (http://microrna .sanger.ac.uk/sequences/). It was estimated, based on highthroughput sequencing data, that the number of miRNAs expressed in the human brain may well exceed one-thousand [68]. Interestingly, many miRNAs expressed in the human brain are not conserved beyond primates, suggesting a recent evolutionary origin [68]. Although functions have been assigned to only very few brain-specific miRNAs, increasing evidence suggests key roles in normal development, differentiation events, and homeostasis, as well as in related pathological conditions $[11,13,33,36,46,47,52,100]$.

\section{4. miRNA and Neurodegenerative Diseases}

Neurodegenerative diseases result from dysfunction, progressive deterioration, and extensive loss of neurons in the central and/or peripheral nervous system $[10,100]$. In this regard, Alzheimer's disease (AD) [101-104], Parkinson's disease (PD) [105-107], prion diseases [108], amyotrophic lateral sclerosis (ALS) $[109,110]$, and hereditary spastic paraplegia $[111,112]$ may have a genetic or sporadic etiology. Instead, Huntington's disease (HD) $[113,114]$ and metabolic disorders with neurological involvement, such as the GM2-gangliosidoses [115-119], can only be genetically transmitted.

There is now compelling evidence that dysregulation of miRNA networks is implicated in the development and onset of human neurodegenerative diseases (see Table 2 and $[12,120])$. This, in turn, may provide the opportunity to elucidate underlying disease mechanisms and open up novel strategies for therapeutic applications.

4.1. Alzheimer's Disease. AD is the most common form of dementia. While several hypotheses have been proposed to explain the disease's etiology, the causes of $\mathrm{AD}$ and means of stopping its progression are still elusive matters [101104, 121-125]. Features of the disease encompass neuronal loss, intraneuronal neurofibrillary tangles (i.e., aggregates of the microtubule-associated protein tau following hyperphosphorylation), and extracellular deposits of amyloid plaques (i.e., deposits of A $\beta$-peptide) [102, 121-125].

Only $10 \%-15 \%$ of $\mathrm{AD}$ cases represent an inheritable disease which follows an autosomal dominant Mendelian pattern, while the majority arise sporadically. Apparently, the disease may be caused by a genetic predisposition, as shown by the identification of specific DNA mutations in a large number of families [101, 122-125]. Despite a variable etiology, a common pathogenetic cascade resulting from distinct gene defects and/or unknown environmental factors cannot be ruled out. For example, accumulation of the $\mathrm{A} \beta$ peptide, the cause of which is unknown, is consistently observed. In approximately $30 \%$ of sporadic AD patient samples, the expression of BACE1 protein, a secretase associated with the formation of $\mathrm{A} \beta$-peptide, is significantly increased [126].

In $\mathrm{AD}$, several miRNAs exhibit abnormal expression levels, suggesting a dysfunctional orchestration of gene expression [79, 80, 127, 128].

Interestingly, Boissonneault et al. have recently found that miR-298 and miR-328 bind to the $3^{\prime}$-UTR of BACE1 mRNA, thereby producing a regulatory effect on enzyme expression in cultured neuronal (N2a) cells. Presence of both miR-298 and miR-328 in the hippocampus of APPSwe/PS1 mice, a well-documented model for $\mathrm{AD}$, and the observation that their levels of expression decrease with aging suggest that altered levels of these miRNAs may deregulate BACE1 and, in turn, lead to increased $\mathrm{A} \beta$ formation and disease progression [81].

Moreover, BACE1 can be controlled by the miR-29a/b1 cluster, consistent with their inverse pattern of expression observed in sporadic AD patients; in addition, a causal correlation was shown in vitro between this cluster and the appearance of the $\mathrm{A} \beta$ peptide $[12,79,80]$. miRNAs may also be involved in the neuroinflammatory process associated 
TABLE 2: miRNAs involved in neurological diseases.

\begin{tabular}{|c|c|c|c|}
\hline microRNA & Neurological disease & Effect & Reference number \\
\hline miR-29a/b-1 & Alzheimer's disease & downregulation & {$[79]$} \\
\hline miR-128a & Alzheimer's disease & upregulation & {$[80]$} \\
\hline miR-298 & Alzheimer's disease & downregulation & {$[81]$} \\
\hline miR-328 & Alzheimer's disease & downregulation & {$[81]$} \\
\hline miR-146a & Alzheimer's disease & upregulation & {$[82]$} \\
\hline miR-133b & Parkinson's disease & downregulation & {$[83]$} \\
\hline miR-19 & Spinocerebellar ataxia type 1 & downregulation & {$[84]$} \\
\hline miR-101 & Spinocerebellar ataxia type 1 & downregulation & {$[84]$} \\
\hline $\operatorname{miR}-130$ & Spinocerebellar ataxia type 1 & downregulation & {$[84]$} \\
\hline miR-9 & Hungtington's disease & downregulation & {$[85,86]$} \\
\hline miR-1 & Tourette syndrome & deregulation & {$[87]$} \\
\hline miR-206 & Tourette syndrome & deregulation & {$[87]$} \\
\hline miR-21 & Glioblastoma & upregulation & {$[88]$} \\
\hline miR-124 & Glioblastoma & downregulation & {$[89]$} \\
\hline miR-137 & Glioblastoma & downregulation & [89] \\
\hline $\operatorname{miR}-124 a$ & Medulloblastoma & downregulation & {$[90]$} \\
\hline miR-34a & Neuroblastoma & downregulation & {$[91]$} \\
\hline miR-184 & Neuroblastoma & downregulation & {$[92]$} \\
\hline miR-15a & Pituitary adenoma & downregulation & [93-95] \\
\hline miR-16 & Pituitary adenoma & downregulation & [93-95] \\
\hline $\operatorname{miR}-221$ & Glioblastoma & upregulation & {$[88,96-98]$} \\
\hline miR-128 & Glioblastoma & upregulation & {$[88,96-98]$} \\
\hline miR-181a & Glioblastoma & upregulation & {$[88,96-98]$} \\
\hline miR-181b & Glioblastoma & upregulation & {$[88,96-98]$} \\
\hline miR-181c & Glioblastoma & downregulation & {$[88,96-98]$} \\
\hline miR-9 & Medulloblastoma & downregulation & [99] \\
\hline miR-125a & Medulloblastoma & downregulation & [99] \\
\hline
\end{tabular}

with deposition of the $A \beta$-peptide. In this regard, the NF$\mathrm{kB}$-sensitive miRNA-146a, which targets complement factor $\mathrm{H}$, an important repressor of inflammatory responses in the brain, was found to be up-regulated in $\mathrm{AD}$ [82].

Finally, a recent work from Carrettiero et al. shows that miR-128a regulates the cochaperone BAG2 and, in turn, a pathway of degradation for microtubule-associated tau proteins with a propensity for misfolding. BAG2 would normally direct tau toward an ubiquitin-independent pathway and selectively reduce the levels of sarkosyl-insoluble protein [129]. Thus, the observation that miR-128a is upregulated in $\mathrm{AD}$ [80] may highlight a molecular mechanism that underlies tau inclusions in neurodegeneration. Taken together, these findings suggest a mechanistic involvement of miRNAs in both the amyloid and tau hypotheses for $\mathrm{AD}$ pathogenesis.

4.2. Parkinson's Disease (PD). PD is the second most common neurodegenerative disorder, characterized by resting tremor, muscular rigidity, bradykinesia, and impaired balance and coordination [105-107, 130-132]. Other symptoms include dysautonomia, dystonic cramps, and dementia. Typical pathological features are loss of dopaminergic neurons in the substantia nigra (SN) and presence of Lewy bodies, which consist of intracellular inclusions affecting surviving neurons in various areas of the brain [130-132]. Several gene loci have been implicated in autosomal, dominant forms of PD. These include PARK1 and PARK4 (due to a mutation or a triplication of the $\alpha$-synuclein gene [SNCA] on $4 \mathrm{q} 21$ and $4 \mathrm{p} 15$, resp.), PARK3 on 2p13, PARK5 (due to a mutation in the UCHL1 gene) on 4p14, PARK8 (due to a mutation in the LRRK2 gene) on 12q12, PARK10 on 1p, PARK11 on 2q, and PARK13 (due to a mutation in the HTRA2 gene) on $2 \mathrm{p} 12$ [105-107, 133, 134].

The implication of miRNAs in PD is intriguing. In murine models, the competence of embryonic stem cells to differentiate into midbrain dopamine neurons in vitro was shown to be disrupted by Dicer deletion and subsequent suppression of miRNA biogenesis, suggesting a physiological role for miRNAs in cell differentiation and/or survival. These results were confirmed in vivo, using mice conditional for Dicer, which exhibited impaired locomotor activity that recapitulated motility problems observed in PD patients. Through a subtractive approach, performed by comparing miRNA expression profiles in normal human adult versus PD patients midbrains, it was shown that miR-133b is specifically missing in PD and that, based on both overexpression and inhibitory tests in vitro, is likely implicated 
in the maturation and function of dopaminergic neurons $[44,83]$. A markedly reduced expression of miR-133b was found in Aphakia mice [44], a dopaminergic neuron deficiency model, which lack Pitx3 [135], a homeobox transcription factor required for neuron survival and normal motor activity susceptible to polymorphisms associated with sporadic PD [136]. Together, these observations suggest a relationship between miR-133b and Pitx3, which operate through a negative feedback loop, wherein Pitx3 promotes the expression of miR-133b that, in turn, downregulates Pitx3 [83]. While these results point to a functional role of the miR-133b/Pitx3 system in ensuring correct dopaminergic function, miR-133b knock-out mice, which are currently unavailable, would establish the extent of miR-133b impact on $\mathrm{PD}$ etiology.

On the other hand, a more recent study showed that deletion of Dicer in dopaminoceptive neurons of the murine striatum led to aberrant anatomical features (smaller brain, reduced neuron size, astrogliosis) and motor impairments (clasping and ataxia) but, surprisingly, not neurodegeneration [137]. As dysfunction, but not necessarily loss, of dopaminoceptive neurons was previously implicated in PD [138], these observations, taken together, suggest that the link between Dicer, miRNAs, and neurodegeneration is restricted to dopaminergic neurons, thereby pointing to distinct functional roles in dopaminoceptive cells.

Finally, Wang et al. found that in PD brains and in vitro cell models disruption of the binding site for miRNA433 led to increased translation of fibroblast growth factor20 (FGF20). Notably, an FGF20 polymorphism at 8p21.322 was previously identified as a PD risk factor correlated with increased $\alpha$-synuclein expression, and consequently PD onset [139].

4.3. Spinocerebellar Ataxia. Spinocerebellar ataxia type 1 (SCA1), which is caused by the expansion of a CAG repeat encoding glutamine within the gene ATXN1, is characterized by the death of cerebellar Purkinje cells [140]. In eight-week old mice, depletion of Dicer from murine Purkinje neurons is irrelevant to cell function and survival, whereas 13-weekold animals are affected by a progressive degeneration of Purkinje neurons leading to cell death. Further, these older mice develop a slight tremor and mild ataxia, both of which worsen with advancing age [141].

In 2008, Lee et al. found that miR-19, miR-101, and miR-130 coregulate Ataxin-1 protein levels and that their inhibition enhance the cytotoxic effects of polyglutamine (PolyQ)-expanded Ataxin-1 in human cells. Thus, mutations in the miRNA binding sites or the miRNA genes themselves might be linked to neurodegenerative phenotypes as a result of Ataxin-1 accumulation [84]. Consistent with this possibility are earlier results showing that, in both Drosophila and human cells, the elimination of miRNAs via Dicer mutation was followed by enhanced pathogenic polyQ protein toxicity. Altogether, these observations point to a neuroprotective function of miRNAs [142].

4.4. Huntington's Disease (HD). HD is a fatal, hereditary neurodegenerative disorder characterized by involuntary ballistic movements, depression, and dementia [113, 114, 143]. Hallmarks of HD are progressive chorea, rigidity, and frequent accurrence of seizures, emotional problems, loss of cognition, as well as atrophy of the caudate nucleus. The causal factor of HD is a gene mutation consisting of abnormally extended repeats of the CAG sequence within the HTT gene, which translates into a huntingtin protein containing an excessively increased glutamine segment [113, $114,143]$.

Disruption of miRNA homeostasis, most likely in connection with an aberrant functionality of the transcriptional repressor REST, was recently shown to play a dynamic role in HD. In fact, levels of several miRNAs with upstream RE1 sites are decreased in HD patient cortices relative to healthy controls. Interestingly, one of these, the bifunctional, brainenriched miR-9/miR- $9^{*}$ targets two components of the REST complex: miR-9 targets REST and miR-9* targets CoREST $[85,86]$. As a consequence of a markedly altered miRNA expression, target mRNAs are subject to dysregulated levels which, in turn, affect the physiological status of forebrain neurons $[85,86]$.

In 2005, RNA interference was shown to produce therapeutically-relevant effects in HD mouse models [144, 145]. Moreover, McBride et al. reported that RNA interference through miRNA technology, as compared to the shRNA-based approach, is a more appropriate strategy for HD treatment. In particular, shRNAs targeting mutant human HD transgenes were found to cause overt toxicity in the mouse striatum, whereas the same sequences introduced into artificial miRNA expression constructs markedly alleviated the neurotoxic profile without compromising achievement of an efficient silencing effect on the murine HD gene homolog [146].

\section{Other Neurological Diseases}

5.1. Fragile X Mental Retardation. The Fragile X syndrome is one of the most common forms of inherited, X-linked dominant mental retardation affecting approximately one in every 4000 males and 8000 females [147, 148] with reduced penetrance of $80 \%$ and $30 \%$, respectively $[148,149]$. The clinical presentations of Fragile X syndrome include mild to severe mental retardation, that is reflected by IQ values ranging between 20 and 70, some abnormal facial features affecting jaw and ears as well as macroorchidism in postpubescent males [149].

The gene responsible for the Fragile X syndrome, FMR1, encodes a protein, FMRP, that interacts with target RNAs [150] and is implicated in mRNA transport and translational control [148]. In particular, FMRP is linked to the miRNA pathway in light of its association with RISC, as shown in Drosophila [151, 152], and with Argonaute proteins, Dicer and miRNAs, as shown in mammals [153-158]. Indeed, FMRP can act as a miRNA acceptor for Dicer and facilitate the assembly of miRNAs $[154,159,160]$. Thus, the neurodegenerative outcome caused by mutations in FMR1 may give rise to a host of secondary effects mediated by the action of FMRP on associated RNA targets. 
The molecular mechanisms which underlie the pathogenesis of this disorder have yet to be elucidated. However, $\mathrm{Xu}$ et al. reported that miR-124a, a nervous-system-specific miRNA, is modulated, at least partially, by the Drosophila homolog of mammalian FMRP (dFMR1), which was found to associate with miR-124 in vivo [161]. That FMRP could utilize specific miRNAs to regulate the translation of target mRNAs was also confirmed by a recent Drosophila study, in which the bantam miRNA was shown to interact with dFMR1 to regulate the fate of germline stem cells [162].

Further, miR-184 was found to be repressed by MeCP2, a protein that binds to methylated DNA forms and plays an important role in synaptic plasticity [163]. This observation points to a link between miRNA and DNA methylation pathways in the dysregulation of synaptic plasticity, a feature for which there is growing evidence of an important role played by miRNAs [164] and that is observed in the Fragile $\mathrm{X}$ syndrome.

5.2. Tourette Syndrome. The paradigm for a disease caused by a specific miRNA is the G to A transition in the $3^{\prime}$ UTR of the myostatin/growth differentiation factor 8 gene in Texel sheep [87]. This mutation creates a target site for miR-1 and miR-206, which are highly expressed in the skeletal muscle. The downstream effect is the translational inhibition of the myostatin gene, which normally limits muscle growth but in the sheep contributes to muscular hypertrophy. Based on this finding, it may be postulated that a search of human SNP databases will reveal mutations that are potentially able to create or destroy putative miRNA target sites and thereby contribute to phenotypic variation.

Conceivably, some of these mutations may affect neuronal miRNAs. One such example is a rare sequence variant of SLIT and Trk-like 1 (SLITRK1), a candidate gene for Tourette syndrome located on chromosome 13q31.1 which is involved in neural development [165]. Two independent instances of the same mutation in the binding site for the miRNA hsa-miR-189 were detected among a population of unrelated individuals with Tourette syndrome, while absent in 3600 control chromosomes. That this mutation may be implicated in Tourette's syndrome is supported by circumstantial evidence showing an overlapping expression pattern of SLITRK1 mRNA and hsa-miR-189 in several brain regions implicated in the disease [165].

5.3. miRNAs and Tumours of the Nervous System. Several studies found that a high proportion of genomic loci containing miRNA genes exhibit DNA copy number alterations in common cancers [166] and miRNA misexpression has also been described in tumours of the nervous system (see Table 2 and $[88-92,96,167-170])$. miRNAs have been shown to act either as tumor suppressors or oncogenes and, depending on the mRNA target, may accelerate the oncogenic process [167]. A suppressor effect was observed in pituitary adenomas, the most common tumors of the central nervous system, in which down-regulation of miR-15a and miR-16 correlates with tumor size [93-95]. Other miRNAs, such as the miR-155 and miR17-92 cluster, have an oncogenic effect $[171,172]$. The consequence of an upregulation of miR-21 has been characterised in glioblastoma tumor cells [88], wherein the knockdown of miR-21 led to increased apoptotic cell death, suggesting that this miRNA may act as an antiapoptotic player $[88,96,173]$. In addition, miRNA profiling in glioblastoma cells has shown high levels of miR221, miR-128, miR-181a, and miR-181b and low levels of miR-181c [88, 97, 98].

miRNA expression analysis may also be used for medulloblastoma prognosis. Down-regulation of miR-9 and miR125a was observed in aggressive brain malignancy, which results in the activation of medulloblastoma cell growth and arrest of apoptosis by activation of the proproliferative truncated TrkC isoform [99].

Based on these findings, the potential to modulate multiple messages at the same time via miRNA technology would therefore represent an intriguing prospect for cancer treatment.

\section{Concluding Remarks and Prospects}

Contemporary science has embraced RNA as a central element of cellular biology. In addition to the canonical role as an intermediate carrier of information, this molecule may in fact perform catalytic, structural, and regulatory tasks. Hence, over the last decade, unravelling the unique versatility of RNA has renewed impetus towards the concept of an "RNA world", which refers to a self-sustaining replication system, antecedent to DNA and proteins, that was engaged during a hypothetical stage at the origin of life [174-177]. Along with the most recent, stunning advances in RNA biology on several fronts, the discovery of gene expression regulators has opened up a large window into the RNA world. Three main categories of small RNAs, namely, shortinterfering, micro- and piwi-interacting RNAs, have emerged as regulatory players within a structurally and functionally sophisticated, and to some extent overlapping, context [14, 178].

Unlike most of the siRNAs, which silence the same locus from which they derive, the effect of miRNAs is to repress genes unrelated to their own loci. Thus, miRNas are subject to precise sequence requirements for the necessary interaction with heterologous targets. Several approaches exist that can be employed to obtain comprehensive miRNA profiling in cells or tissues [179]; however, the significance of a specific profile may be difficult to interpret, in light of the hundreds of target sequences in the human genome that may be associated with any particular miRNAs. In this regard, computational predictions and simulations have a fundamental impact on experimental miRNA research, considering that the downstream effect of a given miRNA will result from the complex modulation of multiple targets along different pathways prone to cross-talk. Conceivably, experimental and bioinformatic models will continue to evolve to offer large-scale screenings for the identification of the most likely miRNA target(s) under a specific developmental, physiological, environmental, or pathological status. 
Currently, functional characterization of specific miRNAs is facilitated by the existence of first-class reagents such as miRNA mimics and inhibitors, available through several specialized vendors. These reagents, appropriately modified to optimize correct strand utilization by RISC (mimics) and ensure tight binding (inhibitors), can be used to either increase or decrease the activity of specific miRNAs. Corresponding applications can be exceptionally informative with respect to studies on gain (loss)-of-function effects, development of high-throughput screens to select species involved in normal and pathological cellular pathways, and the identification of targets.

However, despite the significant progress in miRNA research in the field of neurodevelopment and neurological diseases, it is still elusive as to whether any of the miRNAs implicated in a neuropathological process is directly involved in the etiology or progression of the disorder. Indeed, aberrant expression of a miRNA could simply be circumstantial. This causality issue can be addressed, for example, through an accurate determination of the frequency of specific miRNA mutations, the definition of temporal and spatial miRNA profiles within multiple pathways in vitro, and the development of appropriate in vivo models.

Based on their functional role in fine-tuning metabolic pathways and genetic networks, miRNAs appear to be suitable tools for use in diagnosis, prognosis, and therapy. The problem is to demonstrate which miRNA sequences should be considered drug discovery targets.

Systemic delivery is another hurdle that must be dealt with. Initially, this problem was common to all RNAbased therapeutics, including antisense oligos and siRNAs (reviewed in [180]). However, second-generation antisense technologies have shown that drug delivery issues can be overcome, as shown by systemic drug distribution following subcutaneous administration.

Specific antisense oligos called antagomirs could be used to affect the activity of miRNA. In this regard, treatment of a mouse model of heart disease with an antagomir against miR-21 prevented heart failure [181], and antagomirs to target glioma angiogenesis has recently been proposed [182]. miRNA-based therapeutics have great potential because of their capability to efficiently silence multiple messages concurrently within an entire disease pathway. Instead, conventional therapies directed at single targets require administration of a plurality of drugs giving rise to complex drug interaction and patient compliance issues.

\section{Acknowledgments}

The authors thank members of the Neurogenetics Laboratory of the Santa Lucia Foundation (Rome, Italy) for critical reading of the manuscript. This work was supported by the Italian Ministero della Salute (Grant no. RF-UMB-2006339457 to Al.O. and An.O.; Grants nos. EBRI.1O, PS05.11, and PS05.21 to An.O.), the Consorzio INBB to Al.O., and the Comitato Telethon Fondazione Onlus, the Amministrazione Autonoma dei Monopoli di Stato (AAMS), and the City of Gubbio, Italy (Grant no. GGP06209 to An. O.).

\section{References}

[1] D. P. Bartel, "microRNAs: genomics, biogenesis, mechanism, and function," Cell, vol. 116, no. 2, pp. 281-297, 2004.

[2] G. Meister, "miRNAs get an early start on translational silencing," Cell, vol. 131, no. 1, pp. 25-28, 2007.

[3] M. Kiriakidou, G. S. Tan, S. Lamprinaki, M. De PlanellSaguer, P. T. Nelson, and Z. Mourelatos, "An mRNA m7G cap binding-like motif within human Ago2 represses translation," Cell, vol. 129, no. 6, pp. 1141-1151, 2007.

[4] G. Mathonnet, M. R. Fabian, Y. V. Svitkin, et al., "microRNA inhibition of translation initiation in vitro by targeting the cap-binding complex eIF4F," Science, vol. 317, no. 5845, pp. 1764-1767, 2007.

[5] R. Thermann and M. W. Hentze, "Drosophila miR2 induces pseudo-polysomes and inhibits translation initiation," Nature, vol. 447, no. 7146, pp. 875-878, 2007.

[6] M. Wakiyama, K. Takimoto, O. Ohara, and S. Yokoyama, "Let-7 microRNA-mediated mRNA deadenylation and translational repression in a mammalian cell-free system," Genes and Development, vol. 21, no. 15, pp. 1857-1862, 2007.

[7] X. C. Ding, J. Weiler, and H. Grosshans, "Regulating the regulators: mechanisms controlling the maturation of microRNAs," Trends in Biotechnology, vol. 27, no. 1, pp. 2736, 2009.

[8] D. J. Guarnieri and R. J. DiLeone, "microRNAs: a new class of gene regulators," Annals of Medicine, vol. 40, no. 3, pp. 197208, 2008.

[9] A. Köhler and E. Hurt, "Exporting RNA from the nucleus to the cytoplasm," Nature Reviews Molecular Cell Biology, vol. 8, no. 10, pp. 761-773, 2007.

[10] A. Orlacchio, G. Bernardi, A. Orlacchio, and S. Martino, "Patented therapeutic RNAi strategies for neurodegenerative diseases of the CNS," Expert Opinion on Therapeutic Patents, vol. 18, no. 10, pp. 1161-1174, 2008.

[11] S. S. Hébert and B. De Strooper, "Molecular biology: miRNAs in neurodegeneration," Science, vol. 317, no. 5842, pp. 11791180, 2007.

[12] S. S. Hébert and B. De Strooper, "Alterations of the microRNA network cause neurodegenerative disease," Trends in Neurosciences, vol. 32, no. 4, pp. 199-206, 2009.

[13] S. K. Singh, "miRNAs: from neurogeneration to neurodegeneration," Pharmacogenomics, vol. 8, no. 8, pp. 971-978, 2007.

[14] R. W. Carthew and E. J. Sontheimer, "Origins and mechanisms of miRNAs and siRNAs," Cell, vol. 136, no. 4, pp. 642655, 2009.

[15] V. N. Kim, J. Han, and M. C. Siomi, "Biogenesis of small RNAs in animals," Nature Reviews Molecular Cell Biology, vol. 10, no. 2, pp. 126-139, 2009.

[16] M. J. Moore and N. J. Proudfoot, "Pre-mRNA processing reaches back to transcription and ahead to translation," Cell, vol. 136, no. 4, pp. 688-700, 2009.

[17] A. Rodriguez, S. Griffiths-Jones, J. L. Ashurst, and A. Bradley, "Identification of mammalian microRNA host genes and transcription units," Genome Research, vol. 14, no. 10A, pp. 1902-1910, 2004.

[18] Y.-K. Kim and V. N. Kim, "Processing of intronic microRNAs," EMBO Journal, vol. 26, no. 3, pp. 775-783, 2007.

[19] X. Cai, C. H. Hagedorn, and B. R. Cullen, "Human microRNAs are processed from capped, polyadenylated transcripts that can also function as mRNAs," RNA, vol. 10, no. 12, pp. 1957-1966, 2004. 
[20] Y. Lee, M. Kim, J. Han, et al., "microRNA genes are transcribed by RNA polymerase II," EMBO Journal, vol. 23, no. 20, pp. 4051-4060, 2004.

[21] U. Ohler, S. Yekta, L. P. Lim, D. P. Bartel, and C. B. Burge, "Patterns of flanking sequence conservation and a characteristic upstream motif for microRNA gene identification," RNA, vol. 10, no. 9, pp. 1309-1322, 2004.

[22] X. Liu, K. Fortin, and Z. Mourelatos, "microRNAs: biogenesis and molecular functions," Brain Pathology, vol. 18, no. 1, pp. 113-121, 2008.

[23] Y. Lee, K. Jeon, J.-T. Lee, S. Kim, and V. N. Kim, “microRNA maturation: stepwise processing and subcellular localization," EMBO Journal, vol. 21, no. 17, pp. 4663-4670, 2002.

[24] A. M. Denli, B. B. J. Tops, R. H. A. Plasterk, R. F. Ketting, and G. J. Hannon, "Processing of primary microRNAs by the microprocessor complex," Nature, vol. 432, no. 7014, pp. 231-235, 2004.

[25] R. I. Gregory, K.-P. Yan, G. Amuthan, et al., "The microprocessor complex mediates the genesis of microRNAs," Nature, vol. 432, no. 7014, pp. 235-240, 2004.

[26] J. Han, Y. Lee, K.-H. Yeom, Y.-K. Kim, H. Jin, and V. N. Kim, "The Drosha-DGCR8 complex in primary microRNA processing," Genes and Development, vol. 18, no. 24, pp. 3016-3027, 2004.

[27] M. Landthaler, A. Yalcin, and T. Tuschl, "The human DiGeorge syndrome critical region gene 8 and its D. melanogaster homolog are required for miRNA biogenesis," Current Biology, vol. 14, no. 23, pp. 2162-2167, 2004.

[28] E. Berezikov, W.-J. Chung, J. Willis, E. Cuppen, and E. C. Lai, "Mammalian mirtron genes," Molecular Cell, vol. 28, no. 2, pp. 328-336, 2007.

[29] K. Okamura, J. W. Hagen, H. Duan, D. M. Tyler, and E. C. Lai, "The mirtron pathway generates microRNA-class regulatory RNAs in Drosophila," Cell, vol. 130, no. 1, pp. 89-100, 2007.

[30] J. G. Ruby, C. H. Jan, and D. P. Bartel, "Intronic microRNA precursors that bypass Drosha processing," Nature, vol. 448, no. 7149, pp. 83-86, 2007.

[31] M. T. Bohnsack, K. Czaplinski, and D. Gorlich, "Exportin 5 is a RanGTP-dependent dsRNA-binding protein that mediates nuclear export of pre-miRNAs," RNA, vol. 10, no. 2, pp. 185 191, 2004.

[32] E. Lund, S. Guttinger, A. Calado, J. E. Dahlberg, and U. Kutay, "Nuclear export of microRNA precursors," Science, vol. 303, no. 5654, pp. 95-98, 2004.

[33] W. Filipowicz, S. N. Bhattacharyya, and N. Sonenberg, "Mechanisms of post-transcriptional regulation by microRNAs: are the answers in sight?" Nature Reviews Genetics, vol. 9, no. 2, pp. 102-114, 2008.

[34] M. Ronshaugen, F. Biemar, J. Piel, M. Levine, and E. C. Lai, "The Drosophila microRNA iab-4 causes a dominant homeotic transformation of halteres to wings," Genes and Development, vol. 19, no. 24, pp. 2947-2952, 2005.

[35] R. Garzon, F. Pichiorri, T. Palumbo, et al., "microRNA fingerprints during human megakaryocytopoiesis," Proceedings of the National Academy of Sciences of the United States of America, vol. 103, no. 13, pp. 5078-5083, 2006.

[36] F.-B. Gao, "Posttranscriptional control of neuronal development by microRNA networks," Trends in Neurosciences, vol. 31, no. 1, pp. 20-26, 2008.

[37] R. J. Johnston Jr. and O. Hobert, "A microRNA controlling left/right neuronal asymmetry in Caenorhabditis elegans," Nature, vol. 426, no. 6968, pp. 845-849, 2003.
[38] R. J. Johnston Jr., S. Chang, J. F. Etchberger, C. O. Ortiz, and O. Hobert, "microRNAs acting in a double-negative feedback loop to control a neuronal cell fate decision," Proceedings of the National Academy of Sciences of the United States of America, vol. 102, no. 35, pp. 12449-12454, 2005.

[39] S. Yekta, I.-H. Shih, and D. P. Bartel, "microRNA-directed cleavage of HOXB8 mRNA," Science, vol. 304, no. 5670, pp. 594-596, 2004.

[40] J. Visvanathan, S. Lee, B. Lee, J. W. Lee, and S.-K. Lee, “The microRNA miR-124 antagonizes the anti-neural REST/SCP1 pathway during embryonic CNS development," Genes and Development, vol. 21, no. 7, pp. 744-749, 2007.

[41] L.-C. Cheng, E. Pastrana, M. Tavazoie, and F. Doetsch, "MiR124 regulates adult neurogenesis in the subventricular zone stem cell niche," Nature Neuroscience, vol. 12, no. 4, pp. 399408, 2009.

[42] N. Vo, M. E. Klein, O. Varlamova, et al., "A cAMP-response element binding protein-induced microRNA regulates neuronal morphogenesis," Proceedings of the National Academy of Sciences of the United States of America, vol. 102, no. 45, pp. 16426-16431, 2005.

[43] H.-Y. M. Cheng, J. W. Papp, O. Varlamova, et al., "microRNA modulation of circadian-clock period and entrainment," Neuron, vol. 54, no. 5, pp. 813-829, 2007.

[44] J. Kim, K. Inoue, J. Ishii, et al., "A microRNA feedback circuit in midbrain dopamine neurons," Science, vol. 317, no. 5842, pp. 1220-1224, 2007.

[45] G. M. Schratt, F. Tuebing, E. A. Nigh, et al., "A brain-specific microRNA regulates dendritic spine development," Nature, vol. 439, no. 7074, pp. 283-289, 2006.

[46] A. Kuzin, M. Kundu, T. Brody, and W. F. Odenwald, "The Drosophila nerfin-1 mRNA requires multiple microRNAs to regulate its spatial and temporal translation dynamics in the developing nervous system," Developmental Biology, vol. 310, no. 1, pp. 35-43, 2007.

[47] X. Cao, G. Yeo, A. R. Muotri, T. Kuwabara, and F. H. Gage, "Noncoding RNAs in the mammalian central nervous system," Annual Review of Neuroscience, vol. 29, pp. 77-103, 2006.

[48] B. L. Davidson and R. L. Boudreau, "RNA interference: a tool for querying nervous system function and an emerging therapy," Neuron, vol. 53, no. 6, pp. 781-788, 2007.

[49] J. C. Pearson, D. Lemons, and W. McGinnis, "Modulating Hox gene functions during animal body patterning," Nature Reviews Genetics, vol. 6, no. 12, pp. 893-904, 2005.

[50] A. J. Giraldez, R. M. Cinalli, M. E. Glasner, et al., "microRNAs regulate brain morphogenesis in zebrafish," Science, vol. 308, no. 5723, pp. 833-838, 2005.

[51] U. Hengst, L. J. Cox, E. Z. Macosko, and S. R. Jaffrey, "Functional and selective RNA interference in developing axons and growth cones," Journal of Neuroscience, vol. 26, no. 21, pp. 5727-5732, 2006.

[52] K. S. Kosik, "The neuronal microRNA system," Nature Reviews Neuroscience, vol. 7, no. 12, pp. 911-920, 2006.

[53] L. Smirnova, A. Gräfe, A. Seiler, S. Schumacher, R. Nitsch, and F. G. Wulczyn, "Regulation of miRNA expression during neural cell specification," European Journal of Neuroscience, vol. 21, no. 6, pp. 1469-1477, 2005.

[54] M. Castoldi, S. Schmidt, V. Benes, et al., "A sensitive array for microRNA expression profiling (miChip) based on locked nucleic acids (LNA)," RNA, vol. 12, no. 5, pp. 913-920, 2006.

[55] S. Griffiths-Jones, "miRBase: the microRNA sequence database," Methods in Molecular Biology, vol. 342, pp. 129138, 2006. 
[56] T. Babak, W. Zhang, Q. Morris, B. J. Blencowe, and T. R. Hughes, "Probing microRNAs with microarrays: tissue specificity and functional inference," $R N A$, vol. 10, no. 11, pp. 1813-1819, 2004.

[57] O. Barad, E. Meiri, A. Avniel, et al., "microRNA expression detected by oligonucleotide microarrays: system establishment and expression profiling in human tissues," Genome Research, vol. 14, no. 12, pp. 2486-2494, 2004.

[58] E. A. Miska, E. Alvarez-Saavedra, M. Townsend, et al., "Microarray analysis of microRNA expression in the developing mammalian brain," Genome Biology, vol. 5, no. 9, article R68, 2004.

[59] L. F. Sempere, S. Freemantle, I. Pitha-Rowe, E. Moss, E. Dmitrovsky, and V. Ambros, "Expression profiling of mammalian microRNAs uncovers a subset of brain-expressed microRNAs with possible roles in murine and human neuronal differentiation," Genome Biology, vol. 5, no. 3, article R13, 2004.

[60] J. Shingara, K. Keiger, J. Shelton, et al., "An optimized isolation and labeling platform for accurate microRNA expression profiling," $R N A$, vol. 11, no. 9, pp. 1461-1470, 2005.

[61] J. M. Thomson, J. Parker, C. M. Perou, and S. M. Hammond, "A custom microarray platform for analysis of microRNA gene expression," Nature Methods, vol. 1, no. 1, pp. 47-53, 2004.

[62] V. G. Tusher, R. Tibshirani, and G. Chu, "Significance analysis of microarrays applied to the ionizing radiation response," Proceedings of the National Academy of Sciences of the United States of America, vol. 98, no. 9, pp. 5116-5121, 2001.

[63] K. K.-H. Farh, A. Grimson, C. Jan, et al., "The widespread impact of mammalian microRNAs on mRNA repression and evolution," Science, vol. 310, no. 5755, pp. 1817-1821, 2005.

[64] H. Hohjoh and T. Fukushima, "Expression profile analysis of microRNA (miRNA) in mouse central nervous system using a new miRNA detection system that examines hybridization signals at every step of washing," Gene, vol. 391, no. 1-2, pp. 39-44, 2007.

[65] P. Landgraf, M. Rusu, R. Sheridan, et al., "A mammalian microRNA expression atlas based on small RNA library sequencing," Cell, vol. 129, no. 7, pp. 1401-1414, 2007.

[66] W. P. Kloosterman and R. H. A. Plasterk, "The diverse functions of microRNAs in animal development and disease," Developmental Cell, vol. 11, no. 4, pp. 441-450, 2006.

[67] Y. Zeng and B. R. Cullen, "Recognition and cleavage of primary microRNA transcripts," Methods in Molecular Biology, vol. 342, pp. 49-56, 2006.

[68] E. Berezikov, F. Thuemmler, L. W. van Laake, et al., "Diversity of microRNAs in human and chimpanzee brain," Nature Genetics, vol. 38, no. 12, pp. 1375-1377, 2006.

[69] S. Griffiths-Jones, "The microRNA registry," Nucleic Acids Research, vol. 32, pp. D109-D111, 2004.

[70] D. B. Dogini, P. A. O. Ribeiro, C. Rocha, T. C. Pereira, and I. Lopes-Cendes, "microRNA expression profile in murine central nervous system development," Journal of Molecular Neuroscience, vol. 35, no. 3, pp. 331-337, 2008.

[71] J.-Y. Yu, K.-H. Chung, M. Deo, R. C. Thompson, and D. L. Turner, "microRNA miR-124 regulates neurite outgrowth during neuronal differentiation," Experimental Cell Research, vol. 314, no. 14, pp. 2618-2633, 2008.

[72] Q. Shen and S. Temple, "Fine control: microRNA regulation of adult neurogenesis," Nature Neuroscience, vol. 12, no. 4, pp. 369-370, 2009.
[73] G. A. Wayman, M. Davare, H. Ando, et al., "An activityregulated microRNA controls dendritic plasticity by downregulating p250GAP," Proceedings of the National Academy of Sciences of the United States of America, vol. 105, no. 26, pp. 9093-9098, 2008.

[74] R. R. Buss and R. W. Oppenheim, "Role of programmed cell death in normal neuronal development and function," Anatomical Science International, vol. 79, no. 4, pp. 191-197, 2004.

[75] K. C. Martin and K. S. Kosik, "Synaptic tagging-who's it?" Nature Reviews Neuroscience, vol. 3, no. 10, pp. 813-820, 2002.

[76] L. Smirnova, A. Gräfe, A. Seiler, S. Schumacher, R. Nitsch, and F. G. Wulczyn, "Regulation of miRNA expression during neural cell specification," European Journal of Neuroscience, vol. 21, no. 6, pp. 1469-1477, 2005.

[77] R. L. Judson, J. E. Babiarz, M. Venere, and R. Blelloch, "Embryonic stem cell-specific microRNAs promote induced pluripotency," Nature Biotechnology, vol. 27, no. 5, pp. 459461, 2009.

[78] K. D. Wilson, S. Venkatasubrahmanyam, F. Jia, N. Sun, A. J. Butte, and J. C. Wu, "microRNA profiling of human-induced pluripotent stem cells," Stem Cells and Development, vol. 18, no. 5, pp. 749-757, 2009.

[79] S. S. Hébert, K. Horré, L. Nicolaï, et al., "Loss of microRNA cluster miR-29a/b-1 in sporadic Alzheimer's disease correlates with increased BACE1/ $\beta$-secretase expression," Proceedings of the National Academy of Sciences of the United States of America, vol. 105, no. 17, pp. 6415-6420, 2008.

[80] W. J. Lukiw, "Micro-RNA speciation in fetal, adult and Alzheimer's disease hippocampus," NeuroReport, vol. 18, no. 3, pp. 297-300, 2007.

[81] V. Boissonneault, I. Plante, S. Rivest, and P. Provost, "microRNA-298 and microRNA-328 regulate expression of mouse $\beta$-amyloid precursor protein-converting enzyme 1," Journal of Biological Chemistry, vol. 284, no. 4, pp. 19711981, 2009.

[82] W. J. Lukiw, Y. Zhao, and J. G. Cui, "An NF- $\kappa$ Bsensitive micro RNA-146a-mediated inflammatory circuit in alzheimer disease and in stressed human brain cells," Journal of Biological Chemistry, vol. 283, no. 46, pp. 31315-31322, 2008.

[83] S.-L. Ang, "Transcriptional control of midbrain dopaminergic neuron development," Development, vol. 133, no. 18, pp. 3499-3506, 2006.

[84] Y. Lee, R. C. Samaco, J. R. Gatchel, C. Thaller, H. T. Orr, and H. Y. Zoghbi, "miR-19, miR-101 and miR-130 co-regulate ATXN1 levels to potentially modulate SCA1 pathogenesis," Nature Neuroscience, vol. 11, no. 10, pp. 1137-1139, 2008.

[85] A. N. Packer, Y. Xing, S. Q. Harper, L. Jones, and B. L. Davidson, "The bifunctional microRNA miR-9/miR-9* regulates REST and CoREST and is downregulated in Huntington's disease," Journal of Neuroscience, vol. 28, no. 53, pp. 1434114346, 2008.

[86] R. Johnson, C. Zuccato, N. D. Belyaev, D. J. Guest, E. Cattaneo, and N. J. Buckley, "A microRNA-based gene dysregulation pathway in Huntington's disease," Neurobiology of Disease, vol. 29, no. 3, pp. 438-445, 2008.

[87] A. Clop, F. Marcq, H. Takeda, et al., "A mutation creating a potential illegitimate microRNA target site in the myostatin gene affects muscularity in sheep," Nature Genetics, vol. 38, no. 7, pp. 813-818, 2006. 
[88] J. A. Chan, A. M. Krichevsky, and K. S. Kosik, "microRNA21 is an antiapoptotic factor in human glioblastoma cells," Cancer Research, vol. 65, no. 14, pp. 6029-6033, 2005.

[89] J. Silber, D. A. Lim, C. Petritsch, et al., "miR-124 and miR137 inhibit proliferation of glioblastoma multiforme cells and induce differentiation of brain tumor stem cells," BMC Medicine, vol. 6, article 14, 2008.

[90] J. Pierson, B. Hostager, R. Fan, and R. Vibhakar, "Regulation of cyclin dependent kinase 6 by microRNA 124 in medulloblastoma," Journal of Neuro-Oncology, vol. 90, no. 1, pp. 17, 2008.

[91] J. S. Wei, Y. K. Song, S. Durinck, et al., "The MYCN oncogene is a direct target of miR-34a," Oncogene, vol. 27, no. 39, pp. 5204-5213, 2008.

[92] Y. Chen and R. L. Stallings, "Differential patterns of microRNA expression in neuroblastoma are correlated with prognosis, differentiation, and apoptosis," Cancer Research, vol. 67, no. 3, pp. 976-983, 2007.

[93] A. Bottoni, D. Piccin, F. Tagliati, A. Luchin, M. C. Zatelli, and E. C. D. Uberti, "miR-15a and miR-16-1 down-regulation in pituitary adenomas," Journal of Cellular Physiology, vol. 204, no. 1, pp. 280-285, 2005.

[94] A. P. Heaney, "Pituitary tumour pathogenesis," British Medical Bulletin, vol. 75-76, no. 1, pp. 81-97, 2005.

[95] A. Cimmino, G. A. Calin, M. Fabbri, et al., "miR-15 and miR16 induce apoptosis by targeting BCL2," Proceedings of the National Academy of Sciences of the United States of America, vol. 102, no. 39, pp. 13944-13949, 2005.

[96] S. A. Ciafrè, S. Galardi, A. Mangiola, et al., "Extensive modulation of a set of microRNAs in primary glioblastoma," Biochemical and Biophysical Research Communications, vol. 334, no. 4, pp. 1351-1358, 2005.

[97] T. Papagiannakopoulos and K. S. Kosik, "microRNAs: regulators of oncogenesis and stemness," BMC Medicine, vol. 6, article 15,2008

[98] S. Lawler and E. A. Chiocca, "Emerging functions of microRNAs in glioblastoma," Journal of Neuro-Oncology, vol. 92, no. 3, pp. 297-306, 2009.

[99] E. Ferretti, E. De Smaele, A. Po, et al., "microRNA profiling in human medulloblastoma," International Journal of Cancer, vol. 124, no. 3, pp. 568-577, 2009.

[100] N. Bushati and S. M. Cohen, "microRNAs in neurodegeneration," Current Opinion in Neurobiology, vol. 18, no. 3, pp. 292-296, 2008.

[101] C. Patterson, J. W. Feightner, A. Garcia, G.-Y. R. Hsiung, C. MacKnight, and A. D. Sadovnick, "Diagnosis and treatment of dementia: 1. Risk assessment and primary prevention of Alzheimer disease," Canadian Medical Association Journal, vol. 178, no. 5, pp. 548-556, 2008.

[102] A. Orlacchio, G. Bernardi, A. Orlacchio, and S. Martino, "RNA interference as a tool for Alzheimer's disease therapy," Mini-Reviews in Medicinal Chemistry, vol. 7, no. 11, pp. 1166-1176, 2007.

[103] E. Costanzi, S. Martino, E. Persichetti, et al., "Effects of vitamin $\mathrm{C}$ on fibroblasts from sporadic Alzheimer's disease patients," Neurochemical Research, vol. 33, no. 12, pp. 25102515, 2008.

[104] E. A. Rogaeva, S. Premkumar, J. Grubber, et al., "An $\alpha$-2-macroglobulin insertion-deletion polymorphism in Alzheimer disease," Nature Genetics, vol. 22, no. 1, pp. 19-22, 1999.

[105] J. W. Freeman, M. Simmons, and E. Matos, "Parkinson disease: an incremental challenge," South Dakota Medicine, vol. 60 , no. 12, pp. 481-484, 2007.
[106] C. Balducci, L. Pierguidi, E. Persichetti, et al., "Lysosomal hydrolases in cerebrospinal fluid from subjects with Parkinson's disease," Movement Disorders, vol. 22, no. 10, pp. 14811484, 2007.

[107] W. Stamey and J. Jankovic, "Impulse control disorders and pathological gambling in patients with parkinson disease," Neurologist, vol. 14, no. 2, pp. 89-99, 2008.

[108] G. G. Kovacs and H. Budka, "Prion diseases: from protein to cell pathology," American Journal of Pathology, vol. 172, no. 3, pp. 555-565, 2008.

[109] V. B. Tripathi and A. Al-Chalabi, "Molecular insights and therapeutic targets in amyotrophic lateral sclerosis," CNS and Neurological Disorders-Drug Targets, vol. 7, no. 1, pp. 11-19, 2008.

[110] A. Orlacchio, G. Bernardi, A. Orlacchio, and S. Martino, "Genetics of amyotrophic lateral sclerosis," Recent Research in Developmental Neuroscience, pp. 17-54, 2007.

[111] A. Orlacchio, T. Kawarai, A. Totaro, et al., "Hereditary spastic paraplegia: clinical genetic study of 15 families," Archives of Neurology, vol. 61, no. 6, pp. 849-855, 2004.

[112] A. Orlacchio, T. Kawarai, F. Gaudiello, P. H. St. GeorgeHyslop, R. Floris, and G. Bernardi, "New locus for hereditary spastic paraplegia maps to chromosome 1p31.1-1p21.1," Annals of Neurology, vol. 58, no. 3, pp. 423-429, 2005.

[113] E. C. Stack and R. J. Ferrante, "Huntington's disease: progress and potential in the field," Expert Opinion on Investigational Drugs, vol. 16, no. 12, pp. 1933-1953, 2007.

[114] E. J. Wild and S. J. Tabrizi, "Huntington's disease phenocopy syndromes," Current Opinion in Neurology, vol. 20, no. 6, pp. 681-687, 2007.

[115] S. Martino, C. Emiliani, B. Tancini, et al., "Absence of metabolic cross-correction in Tay-Sachs cells: implications for gene therapy," Journal of Biological Chemistry, vol. 277, no. 23, pp. 20177-20184, 2002.

[116] S. Martino, C. Cavalieri, C. Emiliani, et al., "Restoration of the GM2 ganglioside metabolism in bone marrowderived stromal cells from Tay-Sachs disease animal model," Neurochemical Research, vol. 27, no. 7-8, pp. 793-800, 2002.

[117] S. Martino, P. Marconi, B. Tancini, et al., "A direct gene transfer strategy via brain internal capsule reverses the biochemical defect in Tay-Sachs disease," Human Molecular Genetics, vol. 14, no. 15, pp. 2113-2123, 2005.

[118] S. Martino and A. Orlacchio, "Cellule staminali e GM2 gangliosidosi," Annali dell'Istituto Superiore di Sanità, pp. 27$28,2005$.

[119] S. Martino, I. di Girolamo, C. Cavazzin, et al., "Neural precursor cell cultures from GM2 gangliosidosis animal models recapitulate the biochemical and molecular hallmarks of the brain pathology," Journal of Neurochemistry, vol. 109, no. 1, pp. 135-147, 2009.

[120] M. S. Weinberg and M. J. A. Wood, "Short non-coding RNA biology and neurodegenerative disorders: novel disease targets and therapeutics," Human Molecular Genetics, vol. 18, no. R1, pp. R27-R39, 2009.

[121] M. Goedert and M. G. Spillantini, "A century of Alzheimer's disease," Science, vol. 314, no. 5800, pp. 777-781, 2006.

[122] P. T. Lansbury and H. A. Lashuel, "A century-old debate on protein aggregation and neurodegeneration enters the clinic," Nature, vol. 443, no. 7113, pp. 774-779, 2006.

[123] R. S. Turner, "Alzheimer's disease," Seminars in Neurology, vol. 26, no. 5, pp. 499-506, 2006.

[124] Y. Ohyagi and T. Tabira, "Intracellular amyloid $\beta$-protein and its associated molecules in the pathogenesis of Alzheimer's 
disease," Mini-Reviews in Medicinal Chemistry, vol. 6, no. 10, pp. 1075-1080, 2006.

[125] D. Goldgaber, M. I. Lerman, and O. W. McBride, "Characterization and chromosomal localization of a cDNA encodingbrain amyloid of Alzheimer's disease," Science, vol. 235, no. 4791, pp. 877-880, 1987.

[126] C. E. Hunt and A. J. Turner, "Cell biology, regulation and inhibition of $\beta$-secretase (BACE-1)," FEBS Journal, vol. 276, no. 7, pp. 1845-1859, 2009.

[127] W.-X. Wang, B. W. Rajeev, A. J. Stromberg, et al., "The expression of microRNA miR-107 decreases early in Alzheimer's disease and may accelerate disease progression through regulation of $\beta$-site amyloid precursor proteincleaving enzyme 1," Journal of Neuroscience, vol. 28, no. 5, pp. 1213-1223, 2008.

[128] S. Bicker and G. Schratt, "microRNAs: tiny regulators of synapse function in development and disease," Journal of Cellular and Molecular Medicine, vol. 12, no. 5A, pp. 14661476, 2008.

[129] D. C. Carrettiero, I. Hernandez, P. Neveu, T. Papagiannakopoulos, and K. S. Kosik, "The cochaperone BAG2 sweeps paired helical filament-insoluble tau from the microtubule," Journal of Neuroscience, vol. 29, no. 7, pp. 2151-2161, 2009.

[130] M. M. Hoehn and M. D. Yahr, "Parkinsonism: onset, progression, and mortality," Neurology, vol. 57, no. 10, pp. S11-S26, 2001.

[131] R. L. Nussbaum and M. H. Polymeropoulos, "Genetics of Parkinson's disease,” Human Molecular Genetics, vol. 6, no. 10, pp. 1687-1691, 1997.

[132] M. H. Polymeropoulos, C. Lavedan, E. Leroy, et al., "Mutation in the $\alpha$-synuclein gene identified in families with Parkinson's disease," Science, vol. 276, no. 5321, pp. 20452047, 1997.

[133] V. M. Miller, H. Xia, G. L. Marrs, et al., "Allele-specific silencing of dominant disease genes," Proceedings of the National Academy of Sciences of the United States of America, vol. 100, no. 12, pp. 7195-7200, 2003.

[134] P. Gonzalez-Alegre, V. M. Miller, B. L. Davidson, and H. L. Paulson, "Toward therapy for DYT1 dystonia: allele-specific silencing of mutant Torsin A," Annals of Neurology, vol. 53, no. 6, pp. 781-787, 2003.

[135] P. van den Munckhof, K. C. Luk, L. Ste-Marie, et al., "Pitx3 is required for motor activity and for survival of a subset of midbrain dopaminergic neurons," Development, vol. 130, no. 11, pp. 2535-2542, 2003.

[136] J. Fuchs, J. C. Mueller, P. Lichtner, et al., "The transcription factor PITX3 is associated with sporadic Parkinson's disease," Neurobiology of Aging, vol. 30, no. 5, pp. 731-738, 2009.

[137] T. L. Cuellar, T. H. Davis, P. T. Nelson, et al., "Dicer loss in striatal neurons produces behavioral and neuroanatomical phenotypes in the absence of neurodegeneration," Proceedings of the National Academy of Sciences of the United States of America, vol. 105, no. 14, pp. 5614-5619, 2008.

[138] A. H. Evans and A. J. Lees, "Dopamine dysregulation syndrome in Parkinson's disease," Current Opinion in Neurology, vol. 17, no. 4, pp. 393-398, 2004.

[139] G. Wang, J. M. van der Walt, G. Mayhew, et al., "Variation in the miRNA-433 binding site of FGF20 confers Risk for Parkinson disease by overexpression of $\alpha$-synuclein," American Journal of Human Genetics, vol. 82, no. 2, pp. 283289, 2008.

[140] H. T. Orr and H. Y. Zoghbi, "Trinucleotide repeat disorders," Annual Review of Neuroscience, vol. 30, pp. 575-621, 2007.
[141] A. Schaefer, D. O'Carroll, L. T. Chan, et al., "Cerebellar neurodegeneration in the absence of microRNAs," Journal of Experimental Medicine, vol. 204, no. 7, pp. 1553-1558, 2007.

[142] J. Bilen, N. Liu, and N. M. Bonini, "A new role for microRNA pathways: modulation of degeneration induced by pathogenic human disease proteins," Cell Cycle, vol. 5, no. 24, pp. 2835-2838, 2006.

[143] K. Nakamura and M. J. Aminoff, "Huntington's disease: clinical characteristics, pathogenesis and therapies," Drugs of Today, vol. 43, no. 2, pp. 97-116, 2007.

[144] S. Q. Harper, P. D. Staber, X. He, et al., "RNA interference improves motor and neuropathological abnormalities in a Huntington's disease mouse model," Proceedings of the National Academy of Sciences of the United States of America, vol. 102, no. 16, pp. 5820-5825, 2005.

[145] E. Rodriguez-Lebron, E. M. Denovan-Wright, K. Nash, A. S. Lewin, and R. J. Mandel, "Intrastriatal rAAV-mediated delivery of anti-huntingtin shRNAs induces partial reversal of disease progression in R6/1 Huntington's disease transgenic mice," Molecular Therapy, vol. 12, no. 4, pp. 618-633, 2005.

[146] J. L. McBride, R. L. Boudreau, S. Q. Harper, et al., "Artificial miRNAs mitigate shRNA-mediated toxicity in the brain: implications for the therapeutic development of RNAi," Proceedings of the National Academy of Sciences of the United States of America, vol. 105, no. 15, pp. 5868-5873, 2008.

[147] Y. Li, L. Lin, and P. Jin, "The microRNA pathway and fragile $\mathrm{X}$ mental retardation protein," Biochimica et Biophysica Acta, vol. 1779, no. 11, pp. 702-705, 2008.

[148] S. T. Warren and S. L. Sherman, "The fragile X syndrome," in The Metabolic and Molecular Bases of Inherited Disease, vol. 1, pp. 1257-1290, McGraw-Hill, New York, NY, USA, 2001.

[149] S. T. Warren and D. L. Nelson, "Advances in molecular analysis of fragile X syndrome," Journal of the American Medical Association, vol. 271, no. 7, pp. 536-542, 1994.

[150] G. J. Bassell and S. T. Warren, "Fragile X syndrome: loss of local mRNA regulation alters synaptic development and function," Neuron, vol. 60, no. 2, pp. 201-214, 2008.

[151] A. A. Caudy, M. Myers, G. J. Hannon, and S. M. Hammond, "Fragile X-related protein and VIG associate with the RNA interference machinery," Genes and Development, vol. 16, no. 19, pp. 2491-2496, 2002.

[152] A. Ishizuka, M. C. Siomi, and H. Siomi, "A Drosophila fragile $\mathrm{X}$ protein interacts with components of RNAi and ribosomal proteins," Genes and Development, vol. 16, no. 19, pp. 24972508, 2002.

[153] P. Jin, D. C. Zarnescu, S. Ceman, et al., "Biochemical and genetic interaction between the fragile $\mathrm{X}$ mental retardation protein 3nd the microRNA pathway," Nature Neuroscience, vol. 7, no. 2, pp. 113-117, 2004.

[154] I. Plante, L. Davidovic, D. L. Ouellet, et al., "Dicer-derived microRNAs are utilized by the fragile X mental retardation protein for assembly on target RNAs," Journal of Biomedicine and Biotechnology, vol. 2006, Article ID 64347, 12 pages, 2006.

[155] P. Jin, R. S. Alisch, and S. T. Warren, "RNA and microRNAs in fragile X mental retardation," Nature Cell Biology, vol. 6, no. 11, pp. 1048-1053, 2004.

[156] M. P. Perron and P. Provost, "Protein components of the microRNA pathway and human diseases," Methods in Molecular Biology, vol. 487, pp. 369-385, 2009.

[157] A. Cheever and S. Ceman, "Translation regulation of mRNAs by the fragile $\mathrm{X}$ family of proteins through the microRNA pathway," RNA Biology, vol. 6, no. 2, pp. 175-178, 2009. 
[158] M. Costa-Mattioli, W. S. Sossin, E. Klann, and N. Sonenberg, "Translational control of long-lasting synaptic plasticity and memory," Neuron, vol. 61, no. 1, pp. 10-26, 2009.

[159] R. Duan and P. Jin, "Identification of messenger RNAs and microRNAs associated with fragile $\mathrm{X}$ mental retardation protein," Methods in Molecular Biology, vol. 342, pp. 267-276, 2006.

[160] A. Cheever and S. Ceman, "Phosphorylation of FMRP inhibits association with Dicer," RNA, vol. 15, no. 3, pp. 362366, 2009.

[161] X.-L. Xu, Y. Li, F. Wang, and F.-B. Gao, “The steady-state level of the nervous-system-specific microRNA-124a is regulated by dFMR1 in Drosophila," Journal of Neuroscience, vol. 28, no. 46, pp. 11883-11889, 2008.

[162] Y. Yang, S. Xu, L. Xia, et al., "The bantam microRNA is associated with Drosophila fragile $\mathrm{X}$ mental retardation protein and regulates the fate of germline stem cells," PLoS Genetics, vol. 5, no. 4, article e1000444, 2009.

[163] T. Nomura, M. Kimura, T. Horii, et al., "MeCP2-dependent repression of an imprinted miR-184 released by depolarization," Human Molecular Genetics, vol. 17, no. 8, pp. 11921199, 2008.

[164] N. R. Smalheiser and G. Lugli, "microRNA Regulation of Synaptic Plasticity," NeuroMolecular Medicine, vol. 11, no. 3, pp. 133-140, 2009.

[165] J. F. Abelson, K. Y. Kwan, B. J. O’Roak, et al., "Sequence variants in SLITRK1 are associated with Tourette's syndrome," Science, vol. 310, no. 5746, pp. 317-320, 2005.

[166] L. Zhang, J. Huang, N. Yang, et al., "microRNAs exhibit high frequency genomic alterations in human cancer," Proceedings of the National Academy of Sciences of the United States of America, vol. 103, no. 24, pp. 9136-9141, 2006.

[167] A. Esquela-Kerscher and F. J. Slack, "Oncomirs—microRNAs with a role in cancer," Nature Reviews Cancer, vol. 6, no. 4, pp. 259-269, 2006.

[168] T. Papagiannakopoulos, A. Shapiro, and K. S. Kosik, "microRNA-21 targets a network of key tumor-suppressive pathways in glioblastoma cells," Cancer Research, vol. 68, no. 19, pp. 8164-8172, 2008.

[169] M. S. Nicoloso and G. A. Calin, "microRNA involvement in brain tumors: from bench to bedside," Brain Pathology, vol. 18, no. 1, pp. 122-129, 2008.

[170] G. A. Calin, C. Sevignani, C. D. Dumitru, et al., "Human microRNA genes are frequently located at fragile sites and genomic regions involved in cancers," Proceedings of the National Academy of Sciences of the United States of America, vol. 101, no. 9, pp. 2999-3004, 2004.

[171] S. Volinia, G. A. Calin, C.-G. Liu, et al., "A microRNA expression signature of human solid tumors defines cancer gene targets," Proceedings of the National Academy of Sciences of the United States of America, vol. 103, no. 7, pp. 2257-2261, 2006.

[172] L. He, J. M. Thomson, M. T. Hemann, et al., "A microRNA polycistron as a potential human oncogene," Nature, vol. 435, no. 7043, pp. 828-833, 2005.

[173] G. A. Calin and C. M. Croce, "microRNA signatures in human cancers," Nature Reviews Cancer, vol. 6, no. 11, pp. 857-866, 2006.

[174] C. R. Woese, The Genetic Code, Harper and Row, New York, NY, USA, 1968.

[175] T. A. Lincoln and G. F. Joyce, "Self-sustained replication of an RNA enzyme," Science, vol. 323, no. 5918, pp. 1229-1232, 2009.
[176] P. A. Sharp, “The Centrality of RNA," Cell, vol. 136, no. 4, pp. 577-580, 2009.

[177] T. R. Cech, "Crawling out of the RNA world," Cell, vol. 136, no. 4, pp. 599-602, 2009.

[178] C. D. Malone and G. J. Hannon, "Small RNAs as guardians of the genome," Cell, vol. 136, no. 4, pp. 656-668, 2009.

[179] W. Kong, J.-J. Zhao, L. He, and J. Q. Cheng, "Strategies for profiling microRNA expression," Journal of Cellular Physiology, vol. 218, no. 1, pp. 22-25, 2009.

[180] L. Bonetta, "RNA-based therapeutics: ready for delivery?" Cell, vol. 136, no. 4, pp. 581-584, 2009.

[181] T. Thum, C. Gross, J. Fiedler, et al., "microRNA-21 contributes to myocardial disease by stimulating MAP kinase signalling in fibroblasts," Nature, vol. 456, no. 7224, pp. 980984, 2008.

[182] T. Würdinger and B. A. Tannous, "Glioma angiogenesis: towards novel RNA therapeutics," Cell Adhesion and Migration, vol. 3, no. 2, pp. 230-235, 2009. 

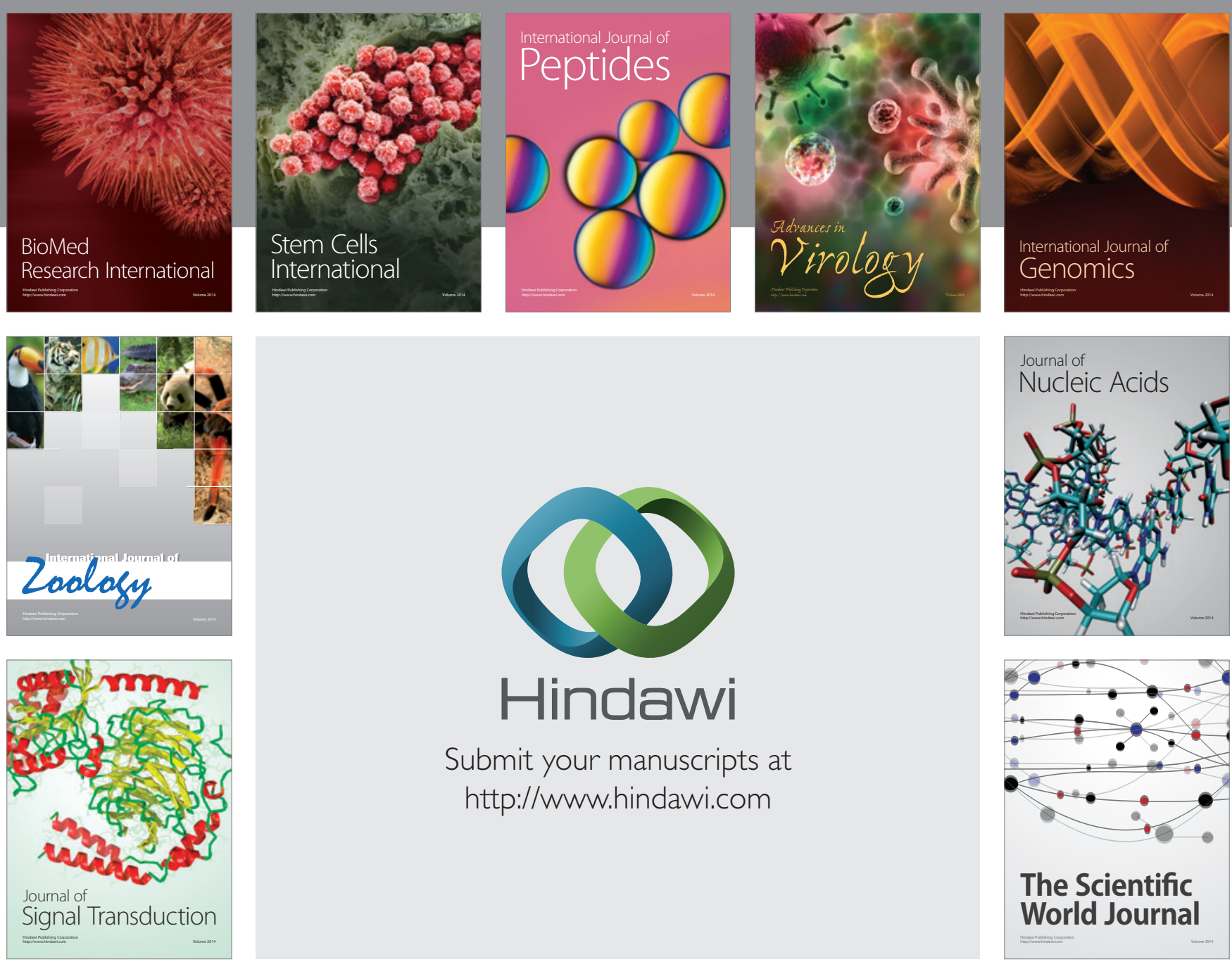

Submit your manuscripts at

http://www.hindawi.com
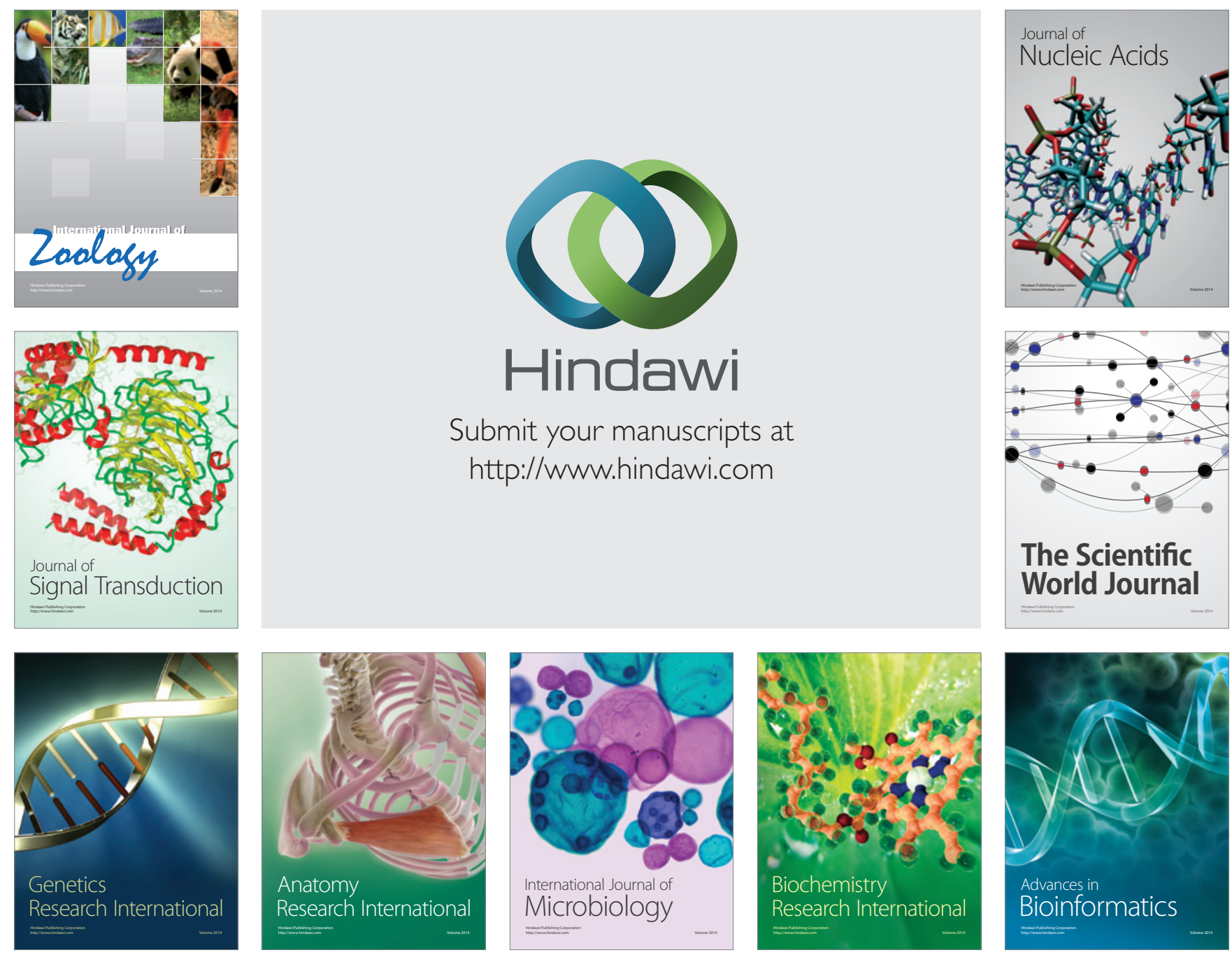

The Scientific World Journal
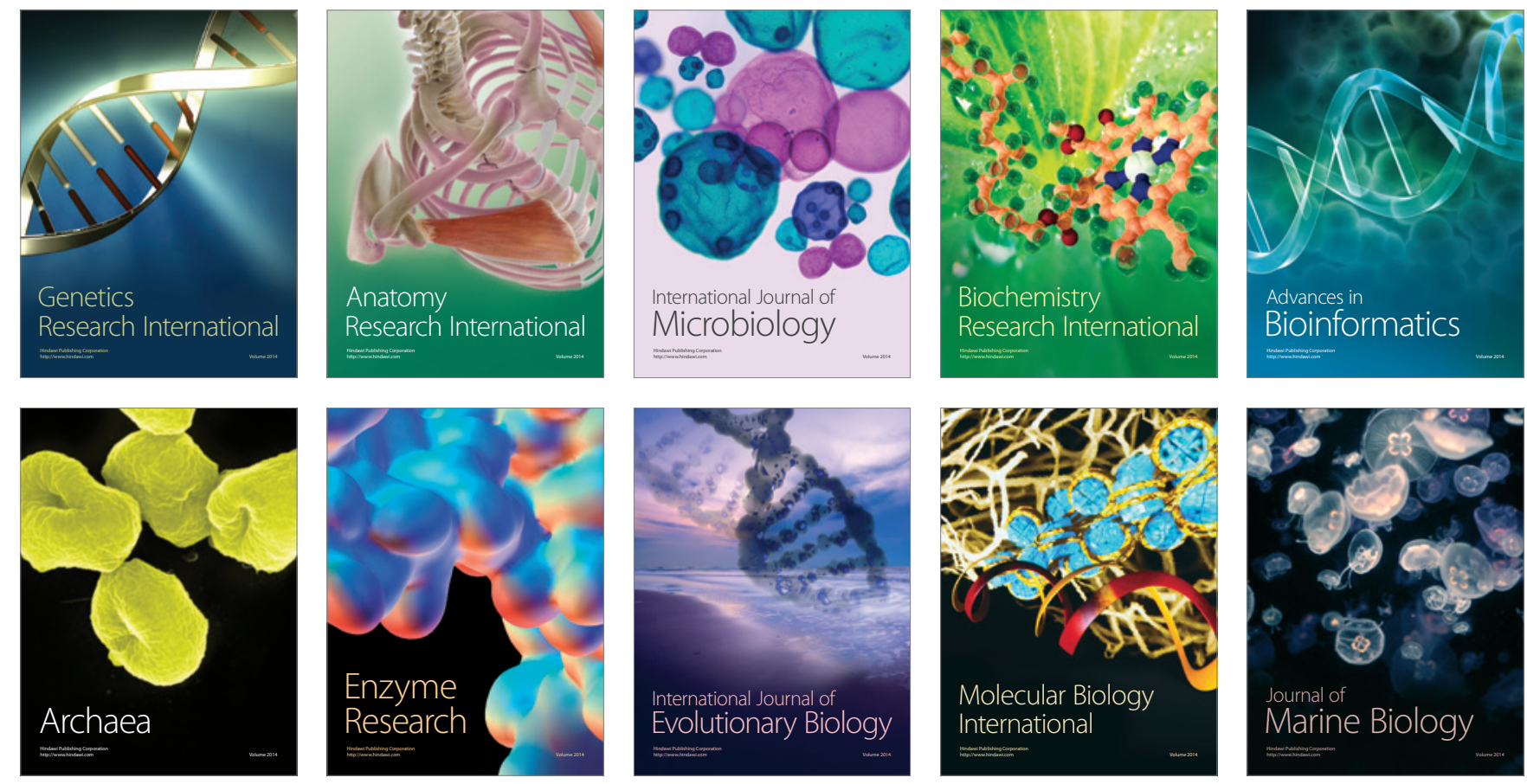